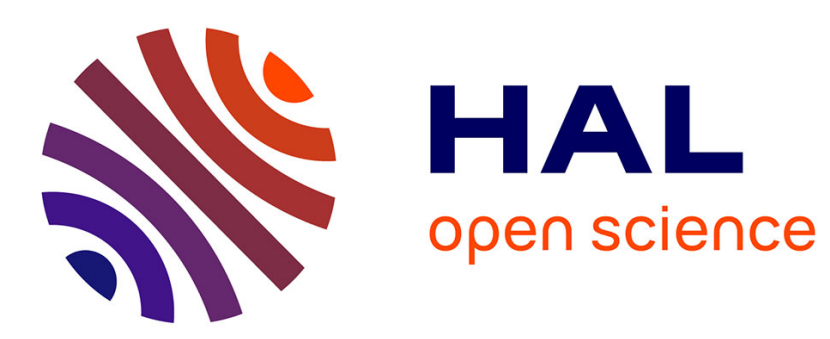

\title{
Stress prevention in adolescence: evaluation of a multimodal training approach
}

Arnold Lohaus

\section{To cite this version:}

Arnold Lohaus. Stress prevention in adolescence: evaluation of a multimodal training approach. Journal of Public Health, 2010, 19 (4), pp.385-388. 10.1007/s10389-010-0391-1 . hal-00615353

\section{HAL Id: hal-00615353 \\ https://hal.science/hal-00615353}

Submitted on 19 Aug 2011

HAL is a multi-disciplinary open access archive for the deposit and dissemination of scientific research documents, whether they are published or not. The documents may come from teaching and research institutions in France or abroad, or from public or private research centers.
L'archive ouverte pluridisciplinaire HAL, est destinée au dépôt et à la diffusion de documents scientifiques de niveau recherche, publiés ou non, émanant des établissements d'enseignement et de recherche français ou étrangers, des laboratoires publics ou privés. 
Stress Prevention in Adolescence: Evaluation of a Multimodal Training Approach

Arnold Lohaus

Department of Psychology, University of Bielefeld, Germany

Running head: Stress Prevention in Adolescents

Address of the first author

Dr. Arnold Lohaus

Department of Psychology

University of Bielefeld

P.O.B. 100131

D-33501 Bielefeld

Tel.: ++49-521-1064515

Fax: ++49-521-1066016

Germany

E-mail: Arnold.Lohaus@uni-bielefeld.de 


\title{
Stress Prevention in Adolescence: Evaluation of a Multimodal Training Approach
}

\begin{abstract}
Subject and Aims. This paper reports on the development and evaluation of a stress prevention program for adolescents of grades 8 and 9. The program is based on the problem-solving approach and was developed on the basis of several evaluation studies. It consists of eight weekly training sessions with durations of 90 minutes each and is accompanied by an e-learning platform.
\end{abstract}

Evaluation Studies. The first section of the paper reports on a preceding demand analysis and the initial development and evaluation of the stress prevention program. The second section summarizes the results of providing an additional e-learning platform. Eight online-lessons were designed in correspondence to the training sessions of the face-to-face intervention. The last section of the paper focuses on the results of an evaluation of an optimized training version including the successful elements of the face-to-face and the elearning platform.

Results and Conclusion. The results of the final evaluation study showed clear knowledge and self-efficacy improvement and reduction of stress symptoms. Moreover, the training led to positive assessments by most adolescents. Possible actions in contributing to an increase of the training effects beyond those already apparent in the current evaluation studies are discussed additionally.

Keywords: $\quad$ Stress Prevention; Adolescence; E-learning; Evaluation 


\section{Introduction}

Adolescents are an important target group for health promotion and for the promotion of somatic and psychological well-being. They are confronted with several major developmental tasks that require readjustments (like achieving emotional independence from parents or achieving new relations with peers of both genders; Kaplan 1999; McNamara 2000). It is thus important to develop appropriate strategies for coping with these new demands. It is also important to avoid the development of inappropriate coping strategies for solving problems (like substance use in dealing with disappointments). Because many coping strategies are established and stabilized during adolescence, this age group can be seen as a core target group for health promotion (Currie, Hurrelmann, Settertobulte, Smith \& Todd 2000).

On the other hand, adolescents form a rather difficult target group for health promotion activities, because many adolescents feel well at the present time and do not see the necessity of promoting their coping behavior to be better adjusted in the future. Moreover, adolescents often show an unrealistic optimism regarding their susceptibility to health problems (Weinstein 1982; 1987). This means that they feel less vulnerable to health problems than others, with the consequence that they are less motivated to care about health promotion activities.

This paper reports on the development of a stress prevention program to promote the coping behavior of adolescents. The program was based on a preceding demand analysis in order to focus on topics and problems seen as relevant by the target group. Moreover, an additional e-learning platform was provided to increase the motivation of the participating adolescents. Thus, several actions were taken to increase the interest and motivation of adolescents to participate in the program. The first section of this paper reports on a demand analysis and the initial development and evaluation of the stress prevention program. The following section summarizes the results of providing an additional e-learning platform, while the last sections focus on the results of an optimized training version including the successful elements of the preceding evaluation studies.

\section{Demand analysis and initial development of a stress prevention training for adolescents}

Before constructing the stress prevention program a demand analysis was conducted to gather information about the willingness of adolescents to participate in such a program and about possibilities to increase their motivation. A total of 1699 children and adolescents of grades 5 to 10 participated in the demand analysis. The results showed that between $25 \%$ and $50 \%$ of the children and adolescents were interested in participating in a stress prevention program, depending on age and gender. The main influential variable was gender, indicating a lower interest in boys as compared to girls. The demand analysis also showed a preference for the school setting as the preferred location for stress prevention training. The selection of topics seen as relevant by the adolescents, the inclusion of diversified activities in the program and the use of innovative methodologies were also evaluated as being important. These preferences were taken into consideration for the construction of the training program.

In consequence, a stress prevention program to be used in school settings was developed. The school setting was not only selected because it was in line with the adolescents' preferences, but also because it provides the opportunity to reach all adolescents and not only those specifically interested in stress prevention. The stress prevention program is characterized by a modular structure with a basic module provided for all adolescents and 
three additional modules which can be selected to fit the demands of the specific target group. All modules consist of four sessions of 90 minutes each. Typically, the basic module is combined with one of the additional modules leading to eight sessions for the participating adolescents. The main target groups are adolescents of grade 8 and 9.

\section{Description of basic and additional modules}

The basic module focuses mainly on a problem-solving approach. The aim is that adolescents do not solve problems spontaneously, but that they first consider possible options for action in problematic situations. The typical steps in a problem-solving approach are (a) to analyse the problem, (b) to search for possible solutions, (c) to identify the advantages and disadvantages of each solution, (d) to execute the optimal solution and (e) to evaluate the results (D'Zurilla \& Goldfried 1971). The adolescents train using this approach on the basis of provided and self-selected problems. The basic module also provides knowledge about stress, stress symptoms and possible coping strategies.

The additional modules are related to (a) cognitive reconstruction, (b) seeking social support and (c) relaxation and time management. Theoretically, problem solving is a meta-strategy to cope with problems, while the additional modules focus on specific strategies (like using relaxation) to be used as specific solutions in the problem solving process. This was the reason for focussing on the problem solving approach as a basic strategy in the basic module.

The additional module on cognitive reconstruction focuses on the relation between thoughts and stress. It contains training elements to stimulate a more positive evaluation of stress-evoking situations and also a more positive self-evaluation. An enhanced self-evaluation may be supportive in being able to see problematic situations in a more positive light.

The additional module on seeking social support is related to mobilizing social support in the case of experienced problems. The focus is not only on support by family or peer group members, but also on institutional support and the search for institutions that may provide support for adolescents. This module focuses also on the promotion of social competencies, because social competencies increase the likelihood of getting social support.

The additional module on relaxation and time management focuses on keeping calm and relaxed as a coping strategy. Therefore, relaxation techniques are introduced to the adolescents, but also techniques to enhance their time management. In the case of relaxation, the Progressive Muscle Relaxation is introduced as a systematic relaxation technique. However, unsystematic methods of relaxation (e.g. listening to music or having fun) are also addressed in this module. Moreover, the adolescents are acquainted with time management techniques.

The program was evaluated in a sample of 461 adolescents of grades 8 to 9 . All combinations of the basic module with each of the additional program modules were compared. A control group without intervention was also included (339 adolescents). Results showed a significant increase in knowledge about stress and coping across all combinations. In addition, more positive thoughts were reported in stress situations and the reported coping behavior changed in the intended direction. There were, however, no effects on the number of reported 
stress symptoms. There were differences between the training combinations showing the most favorable results for cognitive reconstruction and seeking social support. The least favorable results were found for relaxation and time management (Beyer \& Lohaus 2006).

\section{Effects of providing an additional e-learning platform}

Although stress management is a relevant topic for adolescents, the motivation to participate in a stress management program is often weak. On the other hand, adolescents often show high interest in the use of innovative media like the internet (Rideout, Roberts \& Foehr 2005). This was the reason to analyse whether internet-based e-learning in the context of a stress prevention program produced additional effects. Online interventions are characterized by high accessibility as well as interactivity (Taylor, Jobson, Winzelberg \& Abascal 2002). Moreover, low thresholds for participation as well as anonymity are important advantages of internet-delivered mental health promotion (Taylor et al. 2002).

The e-learning platform provided additional contents related to the training. The online-lessons were released weekly during the intervention period and could be used by the adolescents in addition to the face-to-face training. 267 adolescents in grade 7 and 8 participated in the stress prevention program described above. 127 of these adolescents were additionally offered the opportunity to use an e-learning website. An additional 91 adolescents participated in a control group without training. Before and after the training interval, all adolescents were questioned about their knowledge regarding stress and coping. In addition, they had to assess their perceived stress vulnerability, their coping behavior and their stress symptomatology (one week before and one week after as well as two months after the training). The training groups were also asked about their satisfaction with the training.

The results indicate a knowledge increase in the training groups which was stable over time (across two months). The increase was higher in the training group with e-learning than in the group without. Moreover, training satisfaction increased if additional internet support was available. There were, however, no effects on distal variables like assessed stress vulnerability, coping behavior and stress symptomatology (Fridrici \& Lohaus 2008). The results show that it is possible to increase the effects of a stress prevention program in adolescents by supplying additional training contents via e-learning. It is worth noting that also the satisfaction with the training could be increased which may indicate that it was possible to enhance the motivation to participate in the training.

The positive additional effects of the e-learning platform led to the question if it would be possible to replace the classical face-to-face training by an internet based training. Face-to-face training programs require a lot of personnel or time resources and it may thus be difficult to implement them in schools. Thus, an additional study focused on the comparison of the effects of a face-to-face versus an internet based e-learning platform (Fridrici \& Lohaus 2009). A total of 904 adolescents in grades eight and nine was assigned to different treatment conditions (online-training, school-based face-to-face training, control group without intervention). Before and after the training interval, all adolescents were questioned about their knowledge regarding stress and coping and their appraisal of stress-evoking situations. Moreover, the participants had to assess their perceived stress vulnerability, their coping behavior and their stress symptomatology. The training groups were additionally 
questioned about their training acceptance. The results showed a considerable knowledge gain for participants of the online-program. Moreover, the number of positive cognitions in stress-evoking situations increased. However, the overall effects were lower than those in the face-to-face intervention. Regarding training acceptance, the best results were obtained for participants of the face-to-face intervention. In conclusion, webbased prevention or health promotion seems to be no equivalent alternative for school-based face-to-face programs, because neither its effectiveness nor its acceptance among the adolescents is sufficient to substitute a well-implemented face-to-face intervention. Although online-prevention cannot completely substitute schoolbased face-to-face-training it may, however, be seen as an effective complement to conventional methods of health promotion.

\section{Effects of an optimized training version}

As a result of the previous studies, an optimized training version was developed that combined successful elements of the face-to-face training with the e-learning approach. The optimized training version included the basic module from the face-to-face training and additionally those training elements from the other modules that had proved to be of value in the previous evaluation studies (Lohaus, Fridrici \& Maass 2009). The optimized training version consisted of eight weekly training sessions with durations of 90 minutes each and was accompanied by an e-learning platform. 372 adolescents participated in this study. 182 of them participated in the program, while 190 were allocated to the control group. Evaluation criteria were related to changes in the knowledge about stress and coping, stress vulnerability, experience of stress symptoms and self-efficacy. Additional items were related to the evaluation of the training. The evaluation took place one week before, one week after and two months after the training. The results showed clear knowledge and clear self-efficacy improvements and significant reductions regarding stress symptoms. The training led to positive assessments by most adolescents which were significantly more positive than for the initial training version. It is also interesting to note that it was possible to achieve stress symptom reductions which were not possible with the initial version. Thus, the optimized training version indeed led to the intended additional improvements.

The data of this study were reanalysed to examine whether the assumptions of the Transtheoretical Model (TTM; Prochaska \& Velicer 1997; Velicer, Prochaska, Fava, Norman \& Redding 1998) may be useful in evaluating the effectiveness of a stress prevention program in adolescence to promote appropriate coping behaviour (Vierhaus, Maass, Fridrici \& Lohaus 2010). The TTM assumes a movement through a series of phases in the adoption or cessation of behaviour patterns (precontemplation, contemplation, preparation, action and maintenance). It was therefore expected that program participation is associated with a progression through the phases. The results of the reanalysis indicate that the program participation is indeed associated with a progression in phases (although this effect was not stable). Besides this, adolescents in different phases benefit from participation differentially. The conclusion is that a systematic promotion in the different phases of behaviour change by integrating TTMtailored "tools" into a stress management program may improve participants' intention and competence to actually show appropriate coping behaviour.

\section{Conclusion}


The results of the evaluation studies show that it is possible to improve the stress management capabilities of adolescents. It is worth noting that the effects are largely independent of gender, although boys were initially less interested in participating in a stress management program than girls. The most favourable results could be achieved by face-to-face training in combination with an e-learning approach. The additional positive effects of an internet platform on training satisfaction show the importance of actions to increase the motivation and interest of adolescents. As the reanalysis of the data of the final study shows, it may also be useful to construct stage-oriented programs to be in line with the requirements of specific stages in a process of health promotion.

To enhance the motivation of adolescents, it could additionally be important to focus on immediate effects of stress management training, because adolescents are typically not interested in effects that are merely perceivable far in the future. It could also be helpful to use incentives (like participation in a raffle etc.) to increase the motivation and interest of adolescents in health promotion activities (Fridrici, Lohaus \& Glass 2009). To stabilize the effects of health promotion it could be important to include additional booster sessions to remind participants of the program contents. It would also be helpful to integrate standardized programs in a broader context of health promoting activities. The consequence would be that the program effects are not isolated but part of a broader set of activities which could additionally help to stabilize the effects (for example in the context of health-promoting schools).

\section{Acknowledgements}

This study was supported by the German Federal Ministry of Education and Research (Bundesministerium für Bildung und Forschung) and by a Health Insurance Company (Techniker Krankenkasse).

\section{References}

Beyer A, Lohaus A (2006). Stresspräventionstraining im Jugendalter. Hogrefe, Göttingen

Currie C, Hurrelmann K, Settertobulte W, Smith R, Todd J (Eds.). (2000). Health and health behaviour among young people. Issue 1 of the WHO Policy Series: Health policy for children and adolescents. World Health Organization, Copenhagen

D’Zurilla TJ, Goldfried MR (1971). Problem solving and behavior modification. J Abnorm Psychol 78: 107-126

Fridrici M, Lohaus A (2008). Sind Jugendliche „online“ besser zu erreichen? Zur Internetnutzung bei Stresspräventionsmaßnahmen für Jugendliche. Prax Kinderpsychol K 57: 39-59

Fridrici M, Lohaus A (2009). Stress prevention in secondary schools: Online versus face-to-face-training. Health Educ 109: 299-313 
Fridrici M, Lohaus A, Glass C (2009). Effects of incentives in web-based prevention for adolescents: Results of an exploratory field study. Psychol Health 24: 663-675

Kaplan PS (1999). A child's odyssey. Child and adolescent development. Wadsworth, New York

Lohaus A, Fridrici M, Maass A (2009). Stressprävention im Jugendalter: Effekte eines optimierten

Trainingsprogramms mit Internetbegleitung. Z Gesundheitspsych 17: 13-21

McNamara S (2000). Stress in young people. What's new and what can we do? Continuum, London

Prochaska JO, Velicer WF (1997). The Transtheoretical Model of health behavior change. Am J Health Prom 12: $38-48$

Rideout V, Roberts DF, Foehr UG (2005). Generation M: Media in the lives of 8-18 year-olds. Kaiser Family Foundation, Menlo Park

Taylor CB, Jobson KO, Winzelberg A, Abascal L (2002). The use of the Internet to provide evidence-based integrated treatment programs for mental health. Psychiat Ann 32: 671-677

Vierhaus M, Maass A, Fridrici M, Lohaus A (2010). Effects of a stress prevention program addressing adolescents in different phases of behaviour change. Educ Psychol 30: 465-480

Velicer WF, Prochaska JO, Fava JL, Norman GJ, Redding CA (1998). Smoking cessation and stress management: Applications of the Transtheoretical Model of behavior change. Homeostasis 38: 216-233

Weinstein ND (1982). Unrealistic optimism about susceptibility to health problems. J Behav Med 5: 441-460

Weinstein ND (1987). Unrealistic optimism about susceptibility to health problems: Conclusions from a community-wide sample. J Behav Med 10: 481-500

\section{Conflict of interest}

The author declares that there is no conflict of interest. 